\title{
Numerical Analysis of Load Bearing Capacity of Concrete-filled Steel Tubular Columns Exposed to the Standard Fire
}

\author{
HIDEKI UESUGI, MIWA SEKI \\ Department of Architectural Engineering \\ Faculty of Engineering, Chiba University \\ 1-33, Yayoicho, Inage-ku, Chiba-shi, 263, Japan \\ HIRONORI NIWA \\ Technical Research Institute \\ Obayashi Corp. \\ 640 Shimokiyoto 4-chome, Kiyose-shi, Tokyo 204, Japan \\ HIKARU SAITO \\ Department of Architectural Engineering \\ Faculty of Industrial Engineering \\ Nihon University \\ 1-2-1, Izumi-cho, Narashino-shi, Chiba, 275, Japan
}

ABSTRACT

Fire resistance of concrete-filled steel tubular columns is greater than that of unfilled members. But it is required to apply spray fire protection to the same thickness as for non composite steel structures under the present regulations in Japan.

It has been tried to make clear the fire resistance of concrete-filled steel tubular columns under pure compression but the columns must suffer the large bending deflection according to thermal elongation of beams exposed to fire.

In this study it is tried to analyze the loss of load bearing capacity about concrete-filled steel tubular columns under bending deformation and axial force in fire. It is cleared that the loss of the load bearing capacity is due to concrete cracking at inner part of column section induced by thermal expansion at mounting part of column section.

KEYWORDS: fire,concrete-filled steel tubular column, load bearing capacity, stress-deformation behavior, thermal stress, thermal deformation, local buckling,transient strain, concrete cracking

\section{INTRODUCTION}

Concrete-filled steel tubular columns are expected to provide excellent fire resistance performance because inner concrete part of column section could bear the service load if the steel tube part exposed to fire lost the strength. But it is required to spray fire protection to the same thickness as for non-composite steel structures under the present regulations in Japan. However, large deflections in bending also occur at the top and bottom of edge columns due to thermal elongation of beams exposed to fire, shown in Fig.1/1/. For 
simulating these behaviors, the experimental study was carried out subjecting concrete-filled steel tubular columns to both bending and compressive axial forces in fire/ $2 /$.

In this paper,it is tried to analyze these experimental results,especially, the loss of load bearing capacity of concrete-filled steel tubular columns under bending and compression ,using the computer program/1/. Several factors, namely, local buckling of steel tube,transient strain of concrete and strength reduction of filled concrete have been investigated which influence the loss of load bearing capacity of the concrete-filled steel tubular columns.

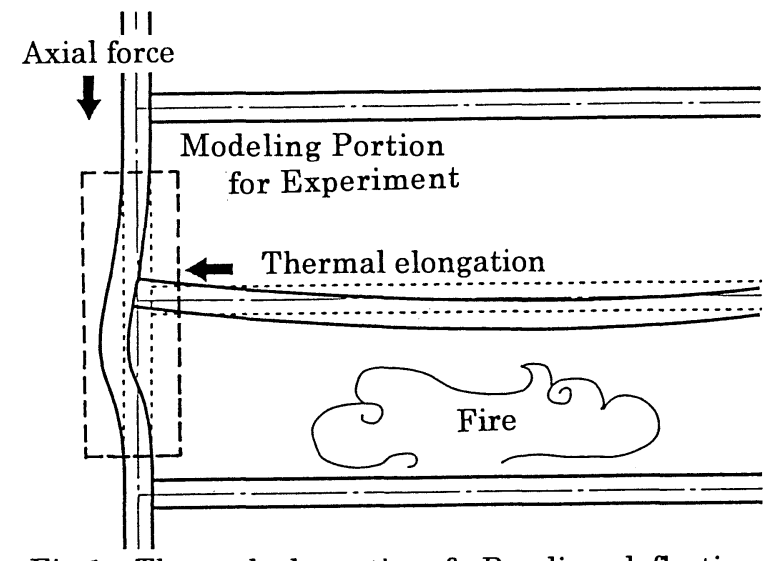

Fig.1 Thermal elongation \& Bending deflection

of Structure exposed to Fire

\section{EXPERIMENTAL DETAIIS}

The outline of the previous experiment/2/ is shown as follows. The portion of the edge column surrounded with the dashed line shown in Fig.1 is considered as the modeling of the experiment.

The shapes and geometries of specimens are shown in Fig.2. A specimen of the concrete-filled steel tubular column has rectangular or circular section. The specimen consists of three parts. One part is testing portion without fire protection and other parts are sufficiently protected against fire.

Fig. 3 shows the loading system used in this experimental study. Loading and heating system consists of the steel frame with 4 oil cylinders and the oil furnace. Both sides of a specimen are supported vertically by 2 oil cylinders and bending deflection is added by the central oil cylinder. One cylinder is set horizontally for producing axial force.

The experimental procedure was firstly carried out by applying an axial force, secondly heating according to the standard fire and thirdly applied bending.Two modes of the bending deflection are applied. One is to apply a constant deflection ratio till the prescribed maximum deflection and maintain this deflection. Another type is to add constant bending force till the prescribed maximum deflection and maintain this deflection. The heating is maintained until a specimen can no longer support the axial force. 

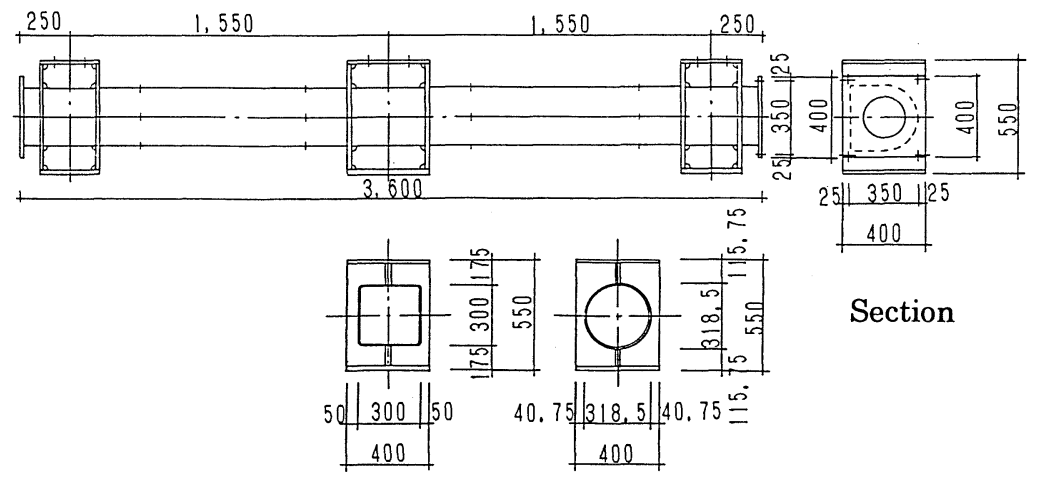

\section{Section}

Fig.2 Shape \& Geometories of Specimen

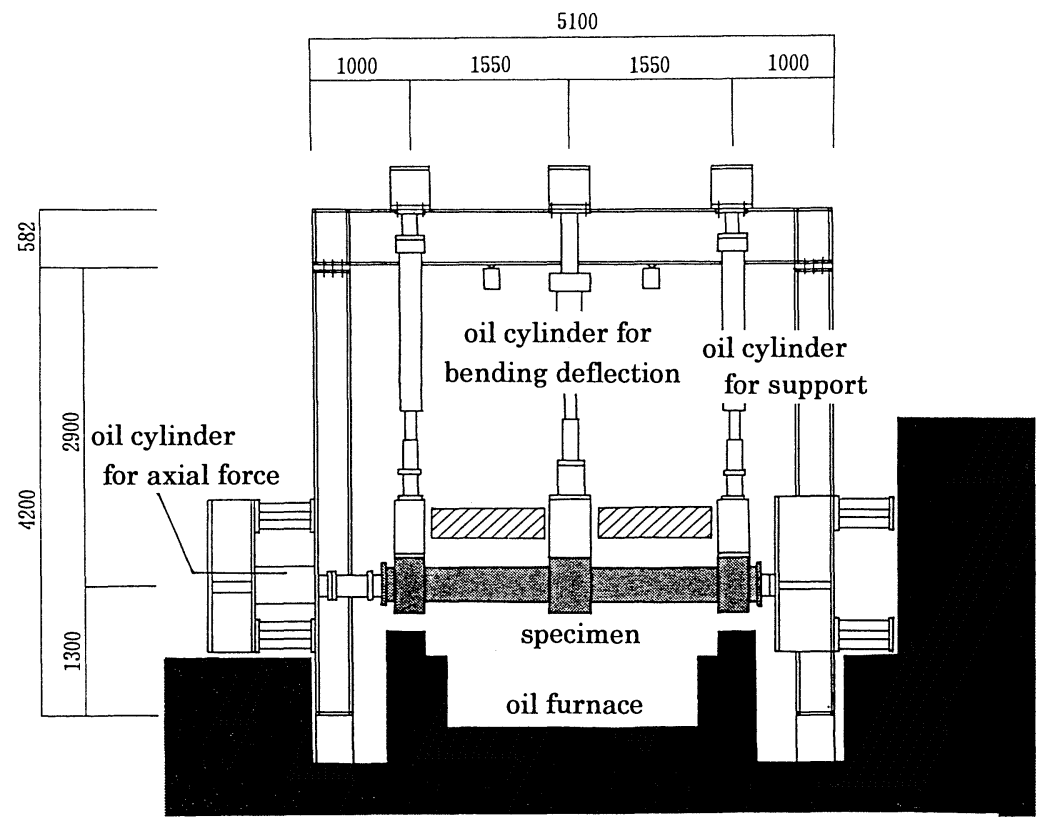

Fig.3 Loading \& Heating System in the Bending Compressing Test

\section{ANALYTICAL METHOD}

Computational analysis was carried out about 20 examples with rectangular or circular section shown in Table 1 and table 2. The analytical method is based on Bernoulli-Euler's hypothesis. Therefore, the effect of bond action between steel tube and inner concrete and shearing collapse of concrete are not considered. 
Table.1 Experimental Results of Concrete-Filled Steel Tubular (Recrtangular Section)

\begin{tabular}{|l|l|c|c|c|c|c|}
\hline $\begin{array}{c}\text { Example } \\
\text { NO. }\end{array}$ & Section shape & $\begin{array}{c}\text { Strength of } \\
\text { concrete } \sigma_{\mathrm{n}} \\
\left(\mathrm{kgf} / \mathrm{cm}^{2}\right)\end{array}$ & $\begin{array}{c}\text { Axial } \\
\text { force N } \\
\text { (tonf) }\end{array}$ & $\begin{array}{c}\text { Axial force } \\
\text { ratio } \\
\text { N/An. } \sigma_{n}\end{array}$ & $\begin{array}{c}\text { Maximam bending } \\
\text { deflection Angle } \\
\text { (ime required /min) }\end{array}$ & $\begin{array}{c}\text { Fire } \\
\text { resistance } \\
\text { time(min) }\end{array}$ \\
\hline$\square-1$ & $\square-300 \times 300 \times 9$ & 354 & 120 & 0.44 & $1 / 100(30)$ & 103 \\
\hline$\square-2$ & $\square-300 \times 300 \times 9$ & 354 & 170 & 0.60 & $1 / 200(30)$ & 39 \\
\hline$\square-3$ & $\square-300 \times 300 \times 9$ & 354 & 127 & 0.45 & $1 / 200(30)$ & 75 \\
\hline$\square-4$ & $\square-300 \times 300 \times 9$ & 334 & 158 & 0.60 & & 39 \\
\hline$\square-4^{\prime}$ & $\square-300 \times 300 \times 9$ & 334 & 158 & 0.60 & $0 / 100$ & 39 \\
\hline$\square-5$ & $\square-300 \times 300 \times 9$ & 334 & 119 & 0.45 & & 71 \\
\hline$\square-55^{\prime}$ & $\square-300 \times 300 \times 9$ & 334 & 119 & 0.45 & $0 / 100$ & 71 \\
\hline$\square-6$ & $\square-300 \times 300 \times 9$ & 334 & 158 & 0.60 & & 35 \\
\hline$\square-6^{\prime}$ & $\square-300 \times 300 \times 9$ & 334 & 158 & 0.60 & $0 / 100$ & 35 \\
\hline$\square-7$ & $\square-300 \times 300 \times 9$ & 334 & 158 & 0.60 & $1 / 200(30)$ & - \\
\hline$\square-8$ & $\square-300 \times 300 \times 9$ & 334 & 158 & 0.60 & $0 / 100$ & 31 \\
\hline$\square-9$ & $\square-300 \times 300 \times 9$ & 334 & 119 & 0.45 & $1 / 100(30)$ & 140 \\
\hline$\square-10$ & $\square-300 \times 300 \times 9$ & 334 & 120 & 0.45 & $1 / 100(60)$ & 119 \\
\hline$\square-11$ & $\square-300 \times 300 \times 9$ & 334 & 120 & 0.45 & $1.5 / 100(45)$ & 80 \\
\hline$\square-12$ & $\square-300 \times 300 \times 9$ & 334 & 107 & 0.40 & $1 / 50$ & 167 \\
\hline
\end{tabular}

Table.2 Experimental Results of Concrete-Filled Steel Tubular (Circular Section)

\begin{tabular}{|l|l|c|c|c|c|c|}
\hline $\begin{array}{c}\text { Example } \\
\text { NO. }\end{array}$ & Section shape & $\begin{array}{c}\text { Strength of } \\
\text { concrete } \sigma_{\mathrm{n}} \\
\left(\mathrm{kg} / \mathrm{cm}^{2}\right)\end{array}$ & $\begin{array}{c}\text { Axial force } \\
\mathrm{N} \\
(\mathrm{tonf})\end{array}$ & $\begin{array}{c}\text { Axial force } \\
\text { ratio } \\
\mathrm{N} / \mathrm{Ac}_{\mathrm{c}} \sigma_{n}\end{array}$ & $\begin{array}{c}\text { Maximam bending } \\
\text { deflection Angle } \\
\text { (Time required /min) }\end{array}$ & $\begin{array}{c}\text { Fire } \\
\text { resistance } \\
\text { time(min) }\end{array}$ \\
\hline $\mathrm{O}-1$ & $\mathrm{O}-318.5 \times 7.9$ & 358 & 117 & 0.45 & $1 / 200(30)$ & 43 \\
\hline $\mathrm{O}-2$ & $\mathrm{O}-318.5 \times 7.9$ & 358 & 117 & 0.45 & $1 / 100(60)$ & 52 \\
\hline $\mathrm{O}-3$ & $\mathrm{O}-318.5 \times 7.9$ & 358 & 155 & 0.60 & $1 / 200(30)$ & 36 \\
\hline $\mathrm{O}-4$ & $\mathrm{O}-318.5 \times 7.9$ & 358 & 117 & 0.45 & $1 / 200(30)$ & 62 \\
\hline $\mathrm{O}-5$ & $\mathrm{O}-318.5 \times 7.9$ & 336 & 109 & 0.45 & $1 / 200(30)$ & 63 \\
\hline $\mathrm{O}-6$ & $\mathrm{O}-318.5 \times 7.9$ & 336 & 48 & 0.20 & $1 / 50$ & 180 \\
\hline $\mathrm{O}-7$ & $\mathrm{O}-318.5 \times 7.9$ & 336 & 73 & 0.30 & $1 / 50$ & 120 \\
\hline $\mathrm{O}-8$ & $\mathrm{O}-318.5 \times 7.9$ & 336 & 97 & 0.40 & $1 / 50$ & 214 \\
\hline
\end{tabular}

\section{3-1 ELEMENT DIVISION OF A ANALYTICAL EXAMPLE}

The analytical model of the column specimen is shown in Fig.4. The column specimen which is heated from 4 sides is divided into 11 small elements shown in Fig.4 . The section of testing portion with no fire protection is divided into about 500 slices as shown in Fig.5, depending upon the sections geometry. The temperature distribution on the section of the testing portion is assumed symmetrical from interpolating of previous experimental data. A set of these temperature history data is shown in Fig.6. 


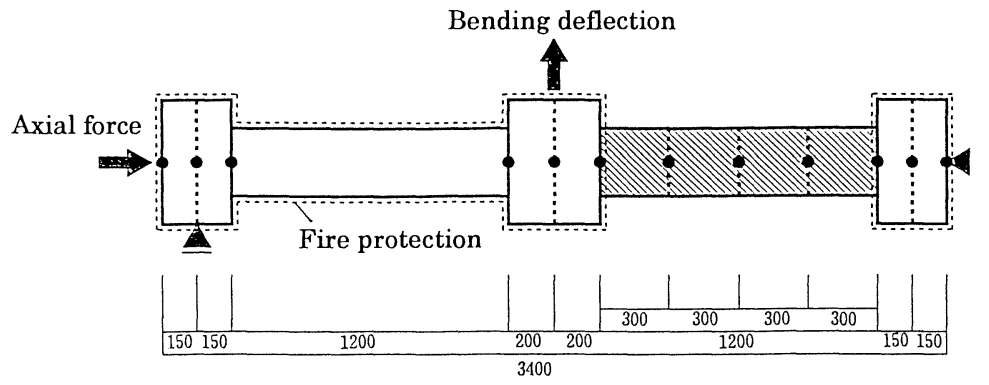

Fig.4 Analytial Model of Column Specimen
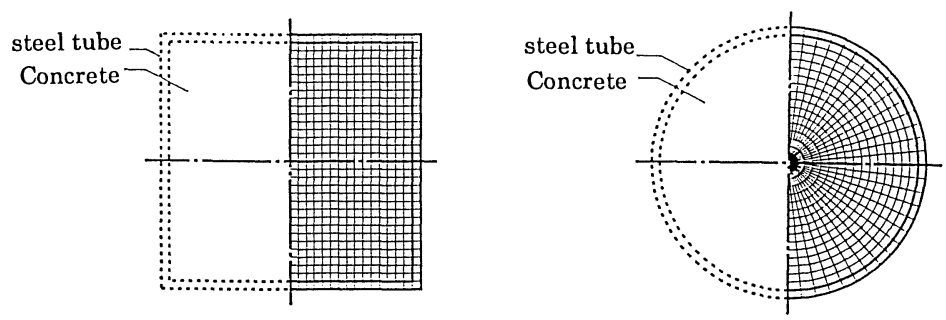

Fig.5 Slice Division on Section of Testing Portion

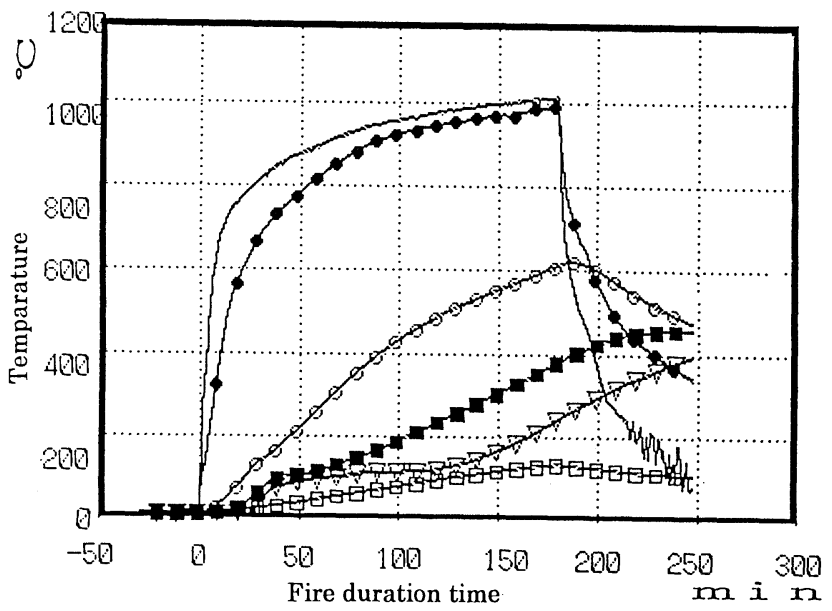

- Average gas temparature in fernace

$-\square-$ Average temparature of steel tube at untested portion

$\longrightarrow$ Average temparature of steel tube at tested portion

- A Average temparature of concrete (Depth $38.25 \mathrm{~cm}$ )

- Average temparature of concrete (Depth $79.25 \mathrm{~cm}$ )

$\rightarrow$ Average temparature of concrete (at Center)

Fig.6 An Example of Temperature Distribution History 
3-2 STRESS-STRAIN CURVE OF STEEL AT ELEVATED TEMPERATURE

There are many experimental data and approximate formulae about the stress-strain curve of steel at the elevated temperature. In this study the stress-strain curve of steel is used which is shown in the literature/3/ and Fig.7. The formula of stress-strain curve is defined as follows,

$$
\begin{aligned}
\varepsilon & =\varepsilon_{e}+\varepsilon_{p} \\
& =\sigma / E_{T}+\left(\sigma / \sigma_{k}\right)^{k}
\end{aligned}
$$

in which each parameters mean next content.

$\varepsilon_{\text {e }}$ : elastic strain

$\varepsilon_{\mathbf{p}}$ : plastic strain

$\sigma:$ stress

$\mathrm{E}_{\mathrm{T}}$ : Young's modulus at elevated temperature

$\sigma_{\mathbf{k}}, \mathrm{k}$ : coefficients which define plastic strain

Values of $\mathrm{E}_{\mathrm{T}}, \sigma_{\mathrm{k}}, \mathrm{k}$ for steel grade SM490 used in this study are shown in Table 3.

Stress reduction due to local buckling of steel tube has appeared in the previous experiment. The stress-strain curve is used which contains the effect of local buckling in compression field. This curve is defined by Suzuki in the literature /4/ as residual strength of post buckling as follows,

$$
\sigma / \sigma_{0}=-\{\sqrt{ }(6.25 /|\varepsilon|)+3.0\} /(\mathrm{b} / \mathrm{t})
$$

in which each parameters mean next content.

$\sigma_{0}:$ the stress depending on the strain of tensile test at same temperature

$\mathrm{b} / \mathrm{t}$ : width-thickness ratio

It is assumed that local buckling occurs when $\sigma / \sigma_{0}$ is equal to -1.0 , Therefore, the critical strain $\varepsilon_{\mathrm{cr}}$ at which local buckling occurs is defined as follows,

$$
\varepsilon_{\mathrm{cr}}=-6.25 /(\mathrm{b} / \mathrm{t}-3.0)^{2}
$$

The stress-strain curves after local buckling are shown with dashed line in Fig. 7 .

Table.3 Value of $\sigma_{\mathrm{k}}, \mathrm{k}(\mathrm{SM} 490)$

\begin{tabular}{|c|c|c|c|}
\hline Temparature $\left({ }^{\circ} \mathrm{C}\right)$ & $E_{Q}\left(\mathrm{kgf} / \mathrm{mm}^{2}\right)$ & $\sigma_{k}\left(\mathrm{kgf} / \mathrm{mm}^{2}\right)$ & $\mathrm{k}$ \\
\hline $\mathrm{RT}$ & 21490 & 46.82 & 17.18 \\
\hline 100 & 21261 & 39.79 & 22.74 \\
\hline 200 & 20545 & 63.23 & 6.97 \\
\hline 300 & 19352 & 83.98 & 4.93 \\
\hline 400 & 17682 & 70.49 & 5.58 \\
\hline 500 & 15534 & 42.15 & 6.95 \\
\hline 600 & 12909 & 24.78 & 7.04 \\
\hline 700 & 9802 & 12.60 & 6.80 \\
\hline 800 & 6224 & 6.30 & 6.75 \\
\hline 900 & 2186 & 2.99 & 7.28 \\
\hline 1000 & 1628 & 1.68 & 6.28 \\
\hline 1100 & 1069 & 0.89 & 5.98 \\
\hline 1200 & 519 & 0.50 & 5.29 \\
\hline
\end{tabular}




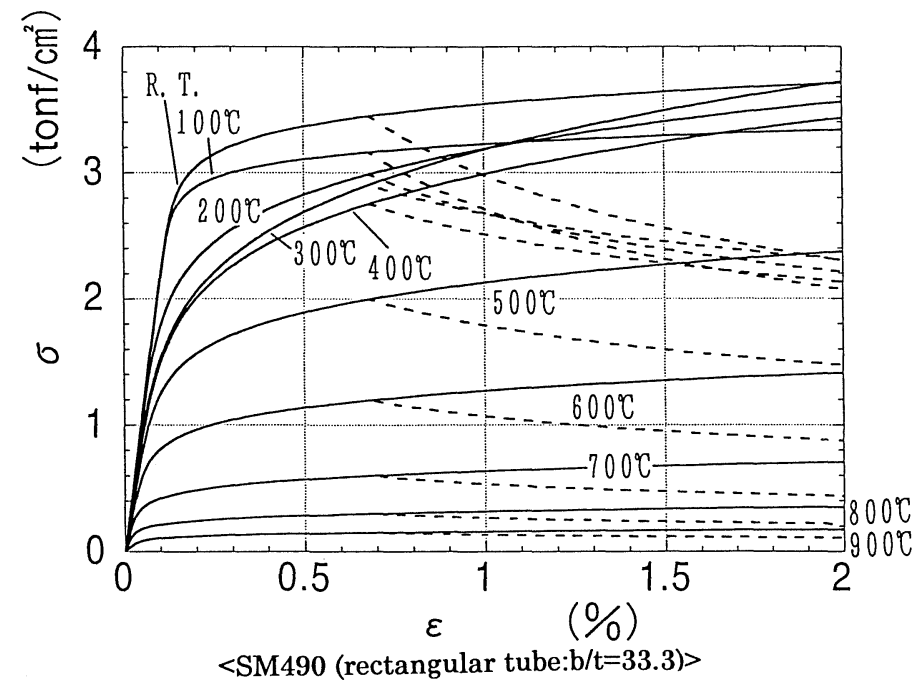

Fig.7 Stress-Strain Carve of Steel at Elevated Temparature

3-3 STRESS-STRAIN CURVE OF CONCRETE AT ELEVATED TEMPERATURE

The stress-strain curve of concrete at elevated temperature is based on Eurocode No.4/5/. The formula of the stress-strain curve is defined as follows,

$$
\begin{aligned}
& \sigma_{c}(\theta)=f_{c}(\theta)\left[\left(\varepsilon_{c}(\theta) / \varepsilon_{c l}(\theta)\right)\right. \\
& *\left\{/\left(2+\left(\varepsilon_{c}(\theta) / \varepsilon \operatorname{cl}(\theta)\right)^{3}\right)\right\} \\
& \sigma_{c}(\theta)=\sigma^{*}+E^{*} \varepsilon=E^{*} \varepsilon_{c r u s h}+E^{*} \varepsilon
\end{aligned}
$$

in which each parameters mean next content.

$\sigma_{c}(\theta)$ :stress of concrete at temperature $\theta^{\circ} \mathrm{C}$

$\varepsilon_{\mathrm{c}}(\theta)$ :strain of concrete at temperature $\theta^{\circ} \mathrm{C}$

$f_{c}(\theta)$ :strength of concrete at temperature $\theta^{\circ} \mathrm{C}$

$\varepsilon \operatorname{cl}(\theta)$ :strain on strength of concrete at temperature $\theta^{\circ} \mathrm{C}$

$\sigma^{*}$ : the stress at $\varepsilon=0$ in the equation (5)

$\mathrm{E}^{*}:$ slope of the second branch of the compression curve

$\varepsilon$ crush:crush strain of concrete

It is assumed that the strain of concrete at elevated temperature is the sum of thermal strain $\varepsilon_{\text {th }}$, instantaneous strain $\varepsilon_{s}$, creep strain $\varepsilon_{\text {creep }}$ and transient strain $\varepsilon_{\mathrm{tr}} / 6 /$, as follows,

$$
\varepsilon=\varepsilon_{t h}+\varepsilon_{s}+\varepsilon_{\text {creep }}+\varepsilon_{t r}
$$

The concept of the transient strain has been presented in the literature/6/ by Anderberg.Y and Thelandersson.S. The transient strain appears proportional to compression stress and thermal strain in the process of temperature rising. One example of the transient strain is formulated as follows $/ 6 \%$,

$$
\varepsilon_{\mathrm{tr}}=-2.35 \varepsilon_{\mathrm{th}} \sigma / \sigma_{\mathrm{uo}}
$$

in which $\sigma_{u 0}$ means the strength of concrete at room temperature/6/. 
$\varepsilon$

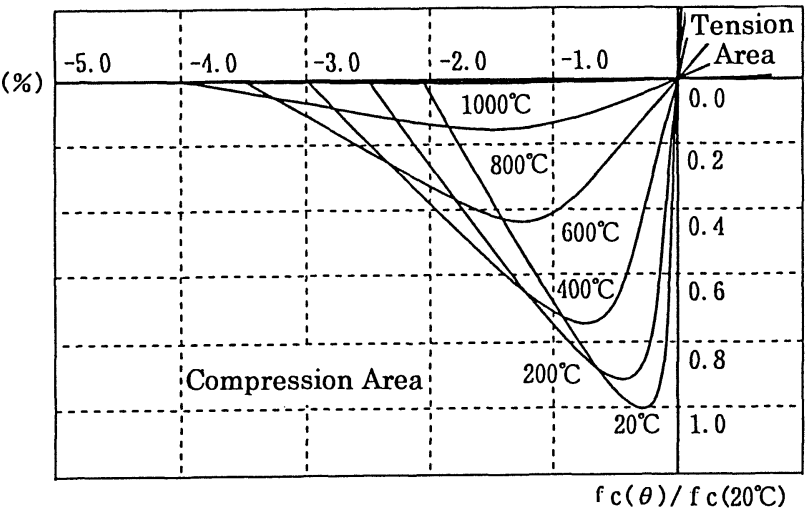

Fig.8 Stress-Strain Curve of Concrete at Elevated Temparature

\section{3-4 REDUCTION OF THE STRENGTH ABOUT FILLED CONCRETE}

Fig.9 shows complex cracking behavior of the center portion of a rectangular steel tube column with $750 \mathrm{~mm}$ width and $2500 \mathrm{~mm}$ length exposed to the standard fire under zero axial force/7/.The temperature of the concrete remained almost at room temperature. Cracking propagation is thought to be due to thermal expansion of the steel tube and outer concrete layer more exposed to the fire.

The mechanism of the cracking growth and reduction strength of the inner concrete are unknown. Therefore, the strength reduction of the inner concrete is treated with parametrically between 1.0 and 0.3 of the concrete strength at room temperature and the influence about the load bearing capacity is investigated numerically in this paper.

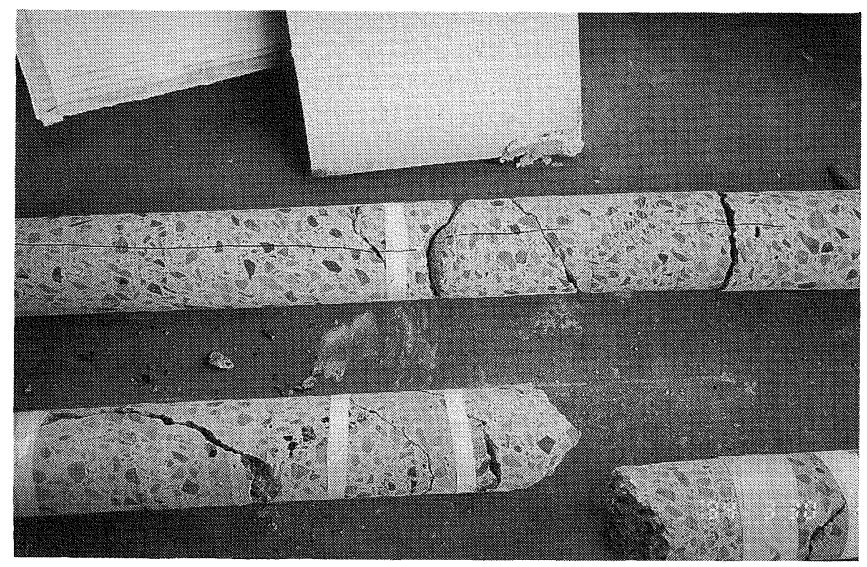

Fig.9 Cracking of Inner Concrete 


\section{3-5 COLLAPSE STRAIN OF CONCRETE}

The crush strain is defined at the loss of concrete strength in Eurocode No.4. In this paper the collapse strain $\varepsilon$ collapse is defined between the crush strain $\varepsilon$ crush and $\varepsilon \operatorname{ci}(\theta)$ strain at the strength of concrete as shown in Fig.10. The collapse strain is formulated as follows,

$$
\varepsilon \operatorname{collapse}=\alpha \cdot \varepsilon \operatorname{cl}(\theta)
$$

in which the collapse parameter $\alpha$ is minimum and equal to 1.0 when the collapse strain is equal to the strain of the concrete strength. The collapse parameter $\alpha$ is maximum and equal to 2.68 at $700{ }^{\circ} \mathrm{C}$ when the ratio of $\varepsilon_{\mathrm{crush}} / \varepsilon_{\mathrm{cl}}(\theta)$ is maximum. The collapse parameter is treated with parametrically between 1.2 and 2.1 and the influence about the load bearing capacity is investigated numerically.

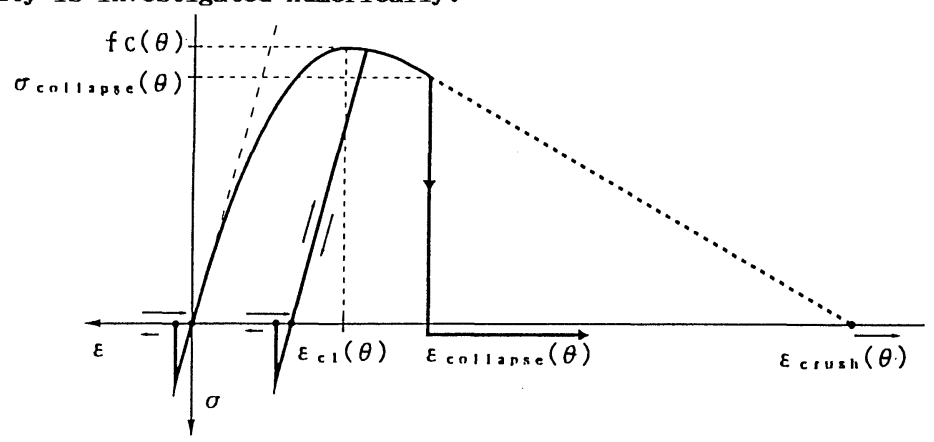

Fig.10 Typical Stress-Strain History of Concrete

\section{ANALYTICAL RESULT}

4 factors are considered in analyzing of the load bearing capacity of concrete-filled steel tubular columns.

(1) local buckling of steel tube

(2) transient strain of concrete

(3) strength reduction of filled concrete

(4) collapse strain parameter of filled concrete

One example No.10 of analytical results is shown in Fig.11 Fig. 14. This example is controlled to arrive at $12 \mathrm{~mm}$ bending deflection equivalent to slope angle $1 / 100$ after 60 minutes of fire duration time under axial force ratio 0.45 , as shown in Table 1 .

\section{4-1 THE EFFECT CONSIDERING THE LOCAL BUCKLING OF STEEL TUBE}

The experimental result and analysis of the local buckling of steel tube is shown in Fig. 11 .

At first stage, the axial elongation of the specimen No.10 is positive caused by the thermal expansion of the steel tube. And at second stage, this elongation returns negative because of the reduction of steel strength and local buckling of steel tube at elevated temperature. At third stage, mild reduction of the axial elongation appears , which is considered that the axial force is transferred from on the steel tube to on the inner concrete. At the last stage, the loss of load bearing capacity happens.

The analytical value is near the experimental one in the first and second stage and separates in the third stage. At the last stage the collapse appears in the experiment but does not appear in the numerical analysis. 


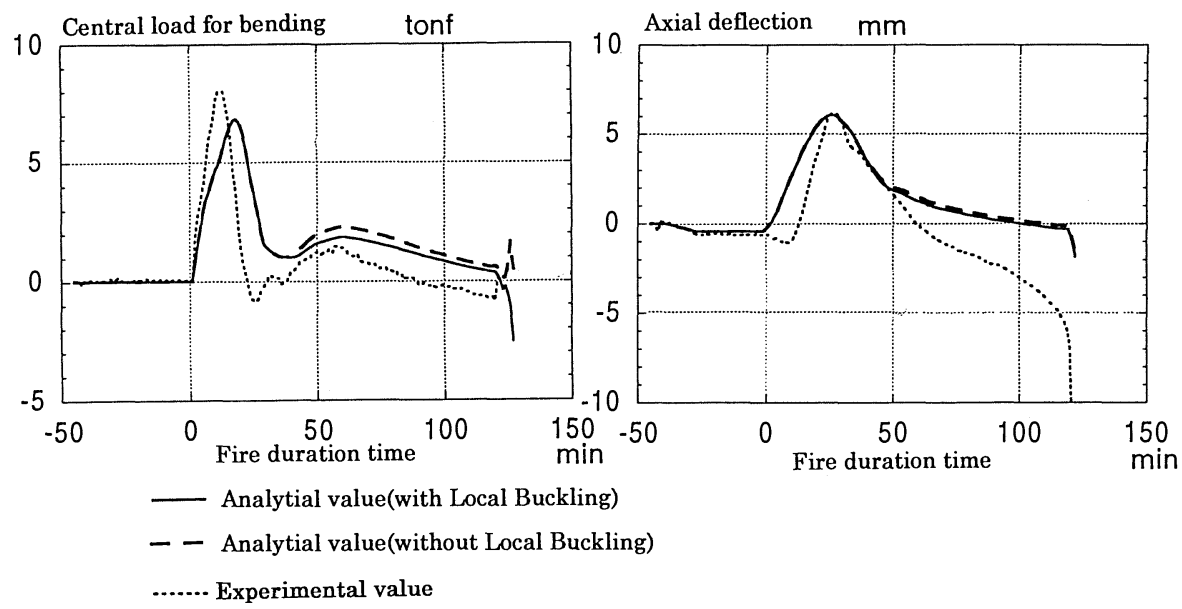

Fig.11 Analytical Results considered Local Buckling of Steel Tube ---Rectangular Section Example 10---

\section{4-2 THE EFFECT CONSIDERING THE TRANSIENT STRAIN}

The experimental result and analytical result one considering the local buckling of steel tube and the transient strain of the concrete is shown in Fig.12.

The axial elongation in the analytical values considering the transient strain of concrete is almost equal to one not considering this strain at the first and second stage. At the third stage the reduction of the axial elongation appears more distinctly caused on the transient strain and gets near to the experiment value.
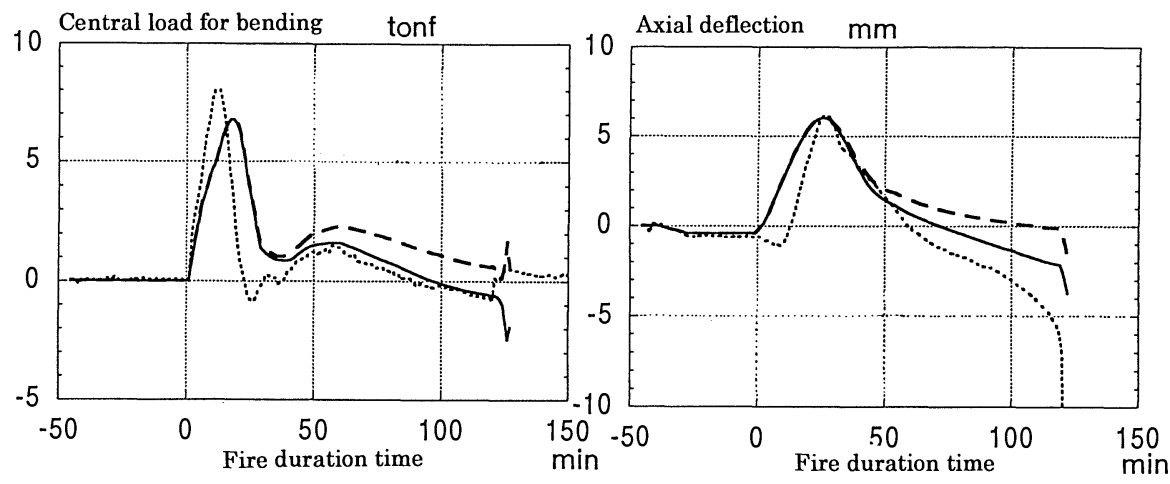

_ Analytial value(with Transient Strain)

- Analytial value(without Transient Strain)

....... Experimental value

Fig.12 Analytical Results considered Transient Strain of Steel Tube ---Rectangular Section Example 10--- 
4-3 THE EFFECT CONSIDERING THE STRENGTH REDUCTION OF FILLED CONCRETE

It is shown in Fig. 13 that the loss of load bearing capacity appears in the analytical example which is considering the strength reduction of filled concrete, adding to the local buckling of steel tube and the transient strain of the concrete. It is evident that the fire resistance time of the concretefilled steel tubular columns is influenced by the strength reduction ratio of filled concrete. This ratio is shown in Fig.14 about all examples classified into 3 groups. In the case of rectangular section columns the strength reduction ratio of concrete is about 0.4 under pure compression and about 0.7 under bending compression. In the case of circular section columns this ratio of concrete is about 0.5 under bending compression.

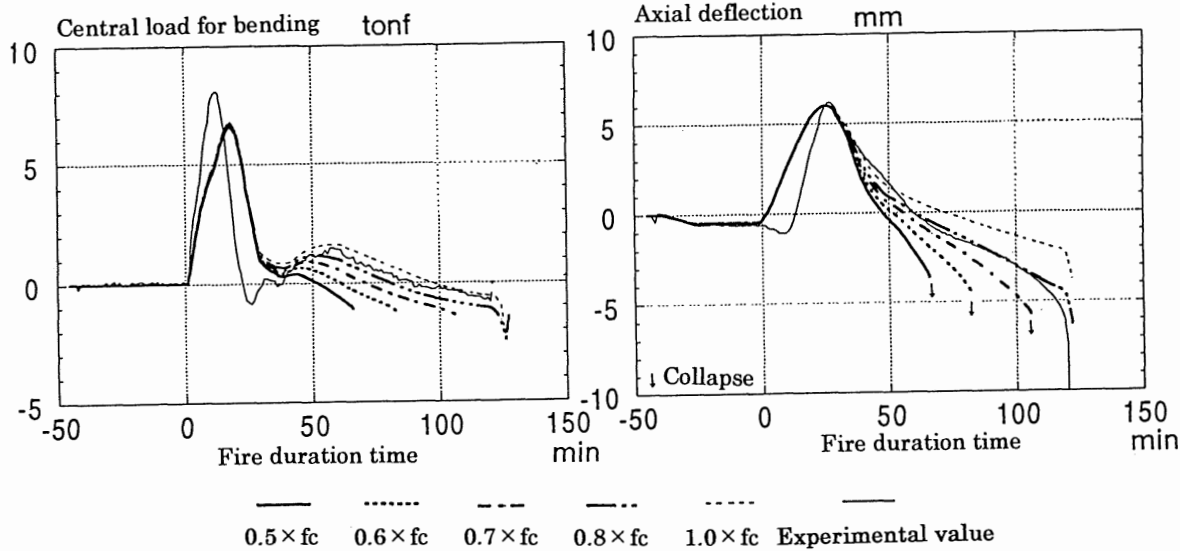

Fig.13 Analytical Results considered Reduce of Concrete Strength ---Rectangular Section Example 10---

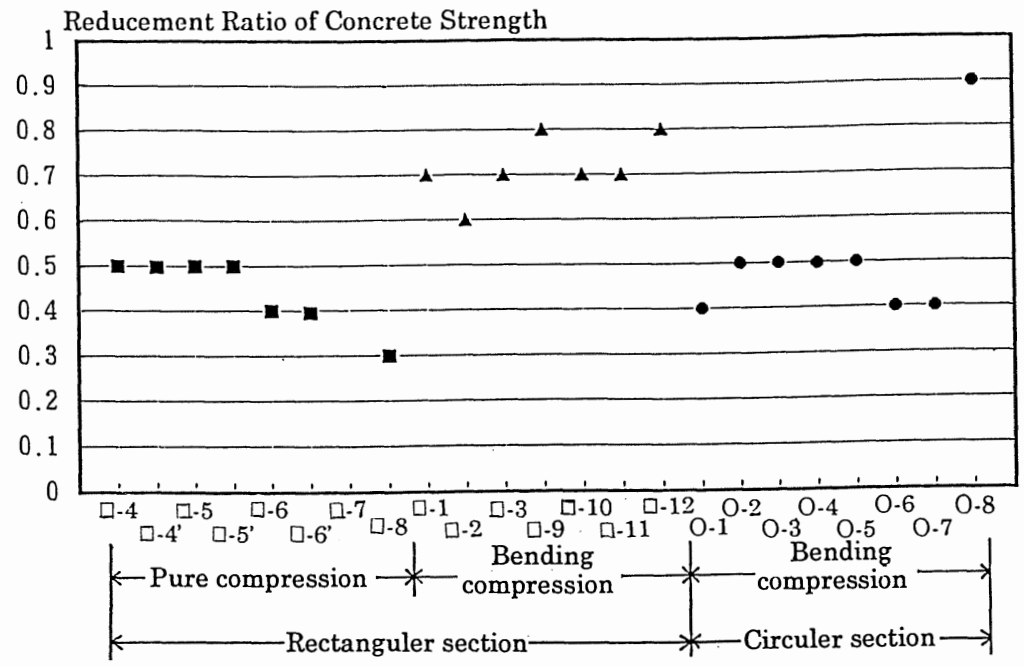

Fig.14 Loss of Load Bearing Capacity \& Reducement Ratio of Concrete Strength 
4-4 THE EFFECT CONSIDERING THE COLLAPSE STRAIN PARAMETER OF FILLED CONCRETE

It is investigated that the collapse strain parameter of filled concrete influences or dose not influence to the loss of load bearing capacity. Fire resistance time is influenced by the collapse strain parameter, only in the examples which show already the collapse caused on the strength reduction of filled concrete. It is shown in Fig. 15 that the loss of load bearing capacity appears correspond to values of the collapse strain parameter $\alpha$.

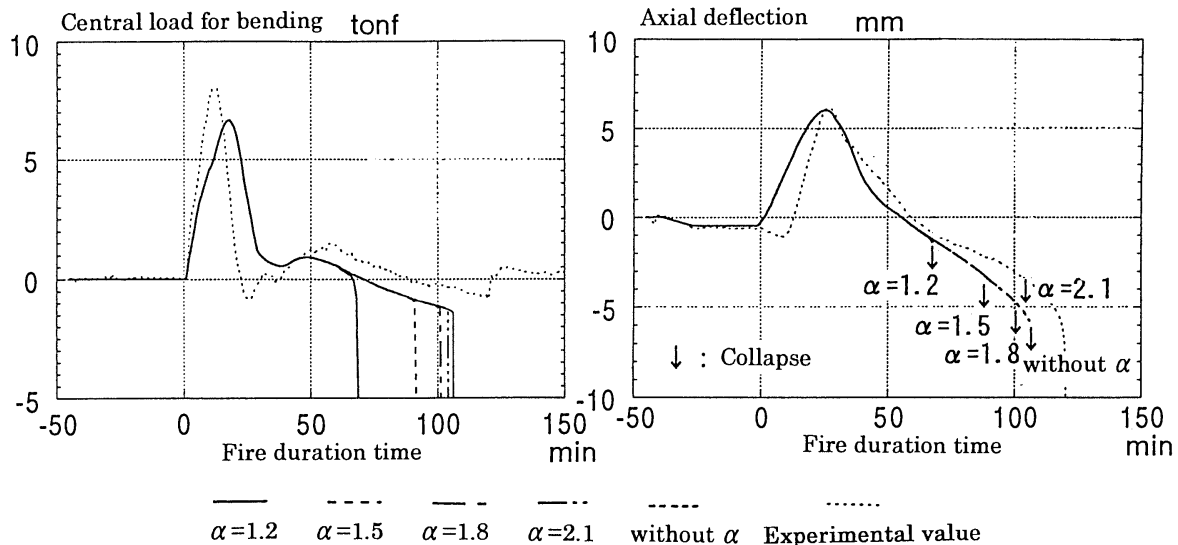

Fig.15 Analytical Results considered Collapse Strain Ratio ---Rectangular Section Example 10---

\section{CONCLUSIONS}

The loss of the load bearing capacity about concrete-filled steel tubular column exposed to the standard fire is brought out,basically, by the strength reduction of filled concrete caused on concrete cracking at inner part of column section induced by thermal expansion at mounting steel part of column section.

\section{REFERENCES}

/1/ H.Saito,H.Uesugi, M. Yamaguchi,A.Kodaira," Thermal Stress and Deformation of Steel Structures of High Rise Buildings in Fire",FIRE SAFETY SCIENCEProceedings of the Second International Symposium,pp.719-728,1988.

/2/ Hideto SAIT0,Hikaru SAIT0,"Fire Resistance of Concrete-Filled Steel Tube Columns under Deformation to Simulate the Elongation of Steel Beams", J .Structr.Eng. ,AIJ, No.458,163-169, Âpr, 1994 .

/3/ J.Hult,"Creep in Engineering Structures",published from Blasdell Publishing Company, A Division of Ginn and Company, 1966.

/4/ H.SUZUKI, "Collapse Temperature of Steel Structure exposed to fire", Annual Report of AIJ,1403-1404,1994.

15/ Commission of European Commities :Eurocode No.4 Design of Composite Structures Part 10; Structural Fire Design,April,1990.

/6/ Anderberg,Y.and Thelandersson, S. , "Stress and Deformation Characteristics of Concrete at High Temperatures 2.Experimental Investigation and material Behavior Model ",Division of Structural Mechanics and concrete Construction, Lund Institute of Technology,Bulletin No.54,Lund,Sweden, 1976.

/7/ "Fire Resistance Test of Concrete-Filled Steel Tubular Columns", Report of Technology Research Center of TAISEI CORPORATION,1995. 